\title{
Research on Evaluation Index and Application of Rockburst Risk in Deep Strip Mining
}

\author{
Bangyou Jiang, ${ }^{1,2}$ Hongguang Ji, ${ }^{3}$ Long Fu, ${ }^{4}$ Shitan Gu $\mathbb{D}^{1,2}$ Tong Zou, ${ }^{1,2}$ and Jiaxin Lu ${ }^{1,2}$ \\ ${ }^{1}$ State Key Laboratory of Mining Disaster Prevention and Control Co-Founded by Shandong Province and \\ the Ministry of Science and Technology, Shandong University of Science and Technology, Qingdao 266590, China \\ ${ }^{2}$ College of Energy and Mining Engineering, Shandong University of Science and Technology, Qingdao 266590, China \\ ${ }^{3}$ School of Civil and Resource Engineering, University of Science and Technology Beijing, Beijing 100083, China \\ ${ }^{4}$ School of Photovoltaics Engineering, Shandong Polytechnic College, Jining 272067, China \\ Correspondence should be addressed to Shitan Gu; chinasdgst@163.com
}

Received 11 March 2020; Revised 22 June 2020; Accepted 8 July 2020; Published 8 September 2020

Academic Editor: Hongwei Yang

Copyright (C) 2020 Bangyou Jiang et al. This is an open access article distributed under the Creative Commons Attribution License, which permits unrestricted use, distribution, and reproduction in any medium, provided the original work is properly cited.

The practice shows that deep strip mining induces rockburst disaster easily. Accurately evaluating rockburst risk of the strip coal pillar is of great significance for ensuring the safety of deep strip mining. In this paper, the catastrophe mechanics model was used to analyze the abrupt instability condition of strip coal pillar. And the three indicators that are the medium stiffness ratio $(k)$ of the elastic and plastic zone in the coal pillar, the plastic zone width ratio $\left(a_{Y}\right)$, and the elastic deformation index $\left(U_{q}\right)$ of core zone were put forward with considering the geometry size of coal pillar. Based on the 3202 panel of Gucheng Coal Mine, the evolution characteristics of rockburst risk of coal pillar under different mining widths and coal pillar widths were studied by numerical simulation. The evaluation result shows that the strip coal pillar of the 3202 panel is in danger of strong rockburst, which is more in line with the actual situation than the results of the traditional rockburst tendency identification test and comprehensive index method. These three indicators can be regarded as important indicators to evaluate the rockburst risk in the strip mining engineering field. Based on that, the design principle of strip mining in Gucheng Coal Mine was put forward, which is considered an important reference for similar cases.

\section{Introduction}

In recent years, with the increasing depletion of shallow coal resources in China, in order to improve mining rate of coal resources and prolong mine life, many mining areas increase the exploitation of coal under buildings, railways, and water bodies, especially in the eastern part of China [1-5]. Strip mining is one of the common mining methods of coal under buildings, railways, and water bodies, which can effectively alleviate the surface subsidence of the coal mining area. Strip mining is widely used in the old eastern mining areas of China, which is one of the research hotspots in the Green Mining of Coal Resources in China. However, under mining disturbance, the high concentrated stress of the strip coal pillar is easy to induce dynamic disasters such as rockburst, which seriously affects the safety production of the working face [6-10].
As a complex nonlinear dynamic disaster, the occurrence of rockburst in coal and rock mass needs to meet certain physical conditions, such as the burst risk of coal and rock mass $[11,12]$. It is of great significance for the prevention and control of rockburst to accurately evaluate the risk of rockburst [13]. In order to quantitatively measure the burst risk of coal and rock, domestic and overseas scholars have proposed a variety of impact propensity indexes based on energy storage, dynamic failure time, deformation, and stiffness of coal and rock and put forward corresponding discrimination indexes [14-16]. Pan et al. [17] put forward three new indexes: impact energy velocity index considering time effect, critical softening region coefficient, and critical stress coefficient. Jiang et al. [18-22] studied the influence of mining supporting pressure and structural stress on the rockburst and adopted a multiparameter early warning 
method to evaluate the rockburst risk of the working face. Lu et al. [23, 24] revealed the mining-induced fault slip mechanism and proposed the multiparameter precursors of a rockburst induced by the fault slip. Zhao et al. [25] established the prediction model of rockburst induced by roof. Yang et al. [26] studied the mechanism of rockburst from the vertical stress of coal pillar. Tan et al. [27] established a cusp catastrophe model for the instability of narrow coal pillars between mining tunnels and strip coal pillars and analyzed the instability mechanism and engineering stability conditions of the coal pillar system of Wongawilli mining. The above studies were based on the characteristics of stress, structure, and roof to establish the rockburst risk assessment model, mainly considering the influence of geological and mining factors on the occurrence of rockburst. However, there are relatively few studies on the dynamic instability characteristics and the main control factors of the strip coal pillar. The existing evaluation methods do not consider the special stress characteristics and instability conditions of the strip coal pillar and lack of pertinence in the evaluation of the rockburst risk of strip mining.

In this study, the medium stiffness ratio of the elastic and plastic zone in coal pillar, the plastic zone width ratio, and the elastic deformation index of kernel zone were put forward based on catastrophe theory, which could be used to guide the prevention and control of rockburst of deep strip working face.

\section{Cusp Catastrophe Model of Strip Coal Pillar}

Rockburst in the coal mine is characterized by abruptness, concealment, no forewarning, and heavy causalities and economic loss [28]. Rockburst is essentially a discontinuous process of sudden instability of the system. Therefore, catastrophe theory can be used to study the process of stope impact instability [29]. For strip coal pillar, with the increase of the width of goaf, the side abutment pressure increases significantly. Under the concentrated load, the coal pillar shows strain softening and remains in a stable position at the initial stage. With the compression deformation of the coal pillar, the deformation energy in the coal pillar gradually accumulates and gradually reaches the unstable critical state. Under the external disturbance, the critical system suddenly jumps to the corresponding stable equilibrium point. The jump phenomenon of the coal pillar system can be considered as the occurrence of rockburst [30].

In order to explore the process of coal pillar rockburst, Tan et al. [27] established the mechanical model of the coal pillar system as shown in Figure 1. In Figure 1, $m$ is the mining thickness of the coal seam, $a$ is the reserved width of the coal pillar, and $b$ is the mining width of the working face, all of which are in meters.

According to the stress-strain curve of the coal pillar, the constitutive relationship between elastic core and plastic zone of coal pillar is different. In order to simplify the calculation, the elastic core of the coal pillar is regarded as linear elastic, the stress-strain curve is a straight line, and the slope of the straight line is the elastic modulus of the coal seam. The plastic zone constitutive relation is approximately

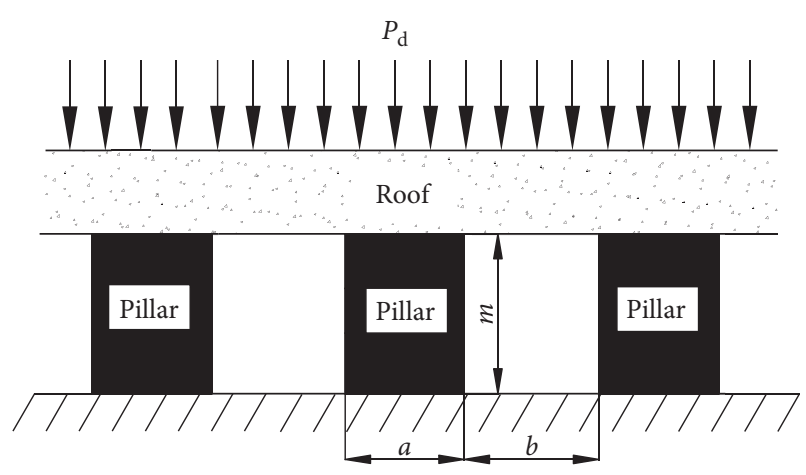

FIgURe 1: Mechanical model of the coal pillar system.

replaced by the strain-softening constitutive relation of coal. The stress-strain relationship of coal pillar can be expressed as

$$
\sigma= \begin{cases}E \mathcal{\varepsilon}, & \left(\varepsilon<\varepsilon_{c}\right), \\ E \varepsilon e^{-\left(\varepsilon / \varepsilon_{c}\right),} & \left(\varepsilon \geq \varepsilon_{c}\right),\end{cases}
$$

where $E$ is the elastic modulus of the coal seam, $\varepsilon$ is the strain of coal pillar, and $\varepsilon_{c}$ is the strain corresponding to the peak stress.

The width of the plastic zone of the coal pillar is defined as $Y$, and then the width of the elastic core of the coal pillar is $a-2 Y$. Considering the influence of coal pillar size, the medium stiffness of the elastic core and the plastic zone of the coal pillar can be expressed as follows:

$$
\left\{\begin{array}{l}
k_{e}=\frac{E(a-2 Y)}{m}, \\
k_{s}=\frac{2 E Y}{m} e^{-\left(u / u_{c}\right)},
\end{array}\right.
$$

where $k_{e}$ is the medium stiffness in the elastic core of the strip coal pillar, $k_{s}$ is the medium stiffness in the plastic zone of the strip coal pillar, $u$ is the deformation value of the coal pillar, and $u_{c}$ is the deformation value of the coal pillar under peak load. Since the height of the coal pillar is $m$, there is $u_{c}=m \varepsilon c$.

According to the research results of Tan et al. [27], the expression of total potential energy function of the system, denoted by $V$, can be expressed as follows:

$$
\begin{aligned}
V= & V_{s}+V_{e}-V_{p}=\frac{E Y}{m} u^{2} e^{-\left(u / u_{c}\right)}+\frac{E(a-2 Y)}{2 m} u^{2} \\
& -\gamma H\left[a+\frac{b}{2}\left(2-\frac{b}{0.6 H}\right)\right] u,
\end{aligned}
$$

where $V_{s}$ is the strain energy of the plastic zone of the strip coal pillar, $V_{e}$ is the elastic potential energy in the elastic nuclear region, and $V_{p}$ is the gravitational potential energy of the overlying strata.

The first derivative of equation (3) is expanded by Taylor series at $u=u_{1}=(3-\sqrt{3}) u_{c}$, the cubic term is extracted, and the following is obtained: 


$$
\begin{aligned}
V^{\prime}= & \frac{\sqrt{3} E Y}{3 m u_{c}^{2}} e^{(\sqrt{3}-3)}\left(u-u_{1}\right)^{3} \\
& +\left[(2-2 \sqrt{3}) \frac{E Y}{m} e^{(\sqrt{3}-3)}+\frac{E(a-2 Y)}{m}\right]\left(u-u_{1}\right) \\
& +\frac{E Y}{m} e^{(\sqrt{3}-3)}(4 \sqrt{3}-6) u_{c}+\frac{E(a-2 Y)}{m}(3-\sqrt{3}) u_{c} \\
& -\gamma H\left[a+\frac{b}{2}\left(2-\frac{b}{0.6 H}\right)\right]=0 .
\end{aligned}
$$

Then, the standard equation of the cusp catastrophe equilibrium surface is obtained and can be expressed as equation (5). Point $u=u_{1}=(3-\sqrt{3}) u_{c}$ is the mutation point of the following equation [27]:

$$
V^{\prime}(x)=x^{3}+p x+q=0 .
$$

In equation (5), $x$ is the state variable, $p$ and $q$ are control variables, and thus

$$
\begin{aligned}
& x=u-u_{1}, \\
& p=(2 \sqrt{3}-6) u_{c}^{2}+\sqrt{3} u_{c}^{2} k, \\
& q=\sqrt{3} u_{c}^{2}\left[(4 \sqrt{3}-6) u_{c}+(3-\sqrt{3}) u_{c} k-\frac{P_{d}}{k_{s}}\right],
\end{aligned}
$$

where $k$ is the ratio of the medium stiffness $k_{e}$ in the elastic core to the medium stiffness $k_{s}$ in the plastic zone of the coal pillar, which is stiffness ratio for short.

According to the mutation theory, only when $p \leq 0$, the system will mutate [31]. So the necessary condition for the system mutation is

$$
\begin{aligned}
& p=(2 \sqrt{3}-6) u_{c}^{2}+\sqrt{3} u_{c}^{2} k \leq 0, \\
& k \leq 2 \sqrt{3}-2 \approx 1.46 .
\end{aligned}
$$

The critical compression of coal pillar before rockburst is denoted by $u_{q}$ and can be expressed as follows:

$$
u_{q}=\left(3-\sqrt{3}-\sqrt{2-\frac{2}{3} \sqrt{3}-\frac{\sqrt{3}}{3} k}\right) u_{c} \text {. }
$$

According to equations (9) and (10), the internal cause of strip pillar rockburst is the stiffness ratio of the elastic-plastic zone which is less than 1.46 caused by strain softening. And the external cause of the coal pillar rockburst is that the deformation energy accumulation caused by the compression deformation of the coal pillar reaches the instability, and the compression of the elastic core of coal pillar reaches or approaches to the critical value. The strain-softening state reflects the failure degree of the coal pillar under load, while the elastic deformation index reflects the magnitude of energy accumulation. Therefore, it is feasible to evaluate the rockburst risk of the coal pillar by using the indexes of strain-softening degree and compression deformation.

\section{Rockburst Risk Evaluation Index of Strip Coal Pillar}

3.1. Medium Stiffness Ratio of Elastic and Plastic Zones in Strip Coal Pillar. At present, the commonly used stiffness ratio index for rockburst risk evaluation of coal and rock is the preyield to postyield stiffness ratio on the stress-strain curve of the coal and rock specimen, denoted by $K_{\mathrm{CF}}$, which reflects the strain-softening degree of the specimen after yield [32]. According to the literature [32], when $K_{\mathrm{CF}}<1$, there is rockburst tendency, and when $K_{\mathrm{CF}}>1$, there is no rockburst tendency, and the detailed division is as follows: $K_{\mathrm{CF}} \geq 1$, no rockburst tendency; $0.5<K_{\mathrm{CF}}<1$, weak and medium rockburst tendency; $K_{\mathrm{CF}}<0.5$, strong rockburst tendency. However, this stiffness ratio index ignores the influence of strip coal pillar size effect, and the evaluation result of rockburst risk is not accurate.

Based on the old stiffness ratio index of rockburst risk evaluation and considering the influence of coal pillar geometry size, this paper proposes a new index, the medium stiffness ratio of the elastic and plastic zone in strip coal pillar, which is denoted by $k$. The physical significance of this index is the ratio of the medium stiffness in the elastic core and the medium stiffness in the plastic zone of the loaded strip coal pillar, which indicates the degree of strain-softening during the loading process of the strip coal pillar. The smaller the $k$ of coal pillar, the greater the rockburst risk. The $k$ can be expressed as follows:

$$
k=\frac{k_{e}}{k_{s}}=\frac{E(a-2 Y) / m}{(2 E Y / m) e^{(\sqrt{3}-3)} .}
$$

According to calculation results of equations (9) and (10), referring to $K_{\mathrm{CF}}$ index, the classification standard of plasticity zone width ratio index is as follows: $k \leq 0.73$, strong rockburst tendency; $0.73<k<1.46$, medium rockburst tendency; $k \geq 1.46$, no rockburst tendency.

3.2. Plastic Zone Width Ratio of Strip Coal Pillar. According to equation (11), it can be predicted that the field application of the stiffness ratio index in the elastic-plastic zone of strip coal pillar is complicated.

By changing the form of equation (11), the necessary condition for rockburst of the strip coal pillar can be obtained as follows:

$$
\frac{Y}{a} \geq 0.354
$$

where $Y$ is the plastic zone width of strip coal pillar and $a$ is the width of strip coal pillar.

In the field application, the width of the plastic zone of the strip coal pillar can be measured by the drilling cuttings method. The larger the width ratio of the plastic zone is, the greater the rockburst risk is. The width ratio of the plastic zone is denoted by $a_{Y}$, which can be expressed as follows:

$$
a_{Y}=\frac{Y}{a} \text {. }
$$


The classification standard of the plasticity zone width ratio index is as follows: $a_{Y} \geq 41.5 \%$, strong rockburst tendency; $35.4 \%<a_{Y}<41.5 \%$, medium rockburst tendency; $a_{Y} \leq 35.4 \%$, no rockburst tendency.

\subsection{Elastic Deformation Index of the Strip Coal Pillar Core} Zone. The elastic deformation index is also one of the commonly used evaluation indexes of rockburst risk of coal and rock. The old elastic deformation index is obtained by the ratio of the elastic deformation to the total deformation under the cyclic loading and unloading test, and the test loading is not less than $80 \%$ of the peak strength of coal and rock [33]. This index reflects the influence of the elastic deformation degree of the specimen on the burst failure. The detailed classification standard of the elastic deformation index which is usually denoted by $K_{i}$ is as follows: $K_{i}>0.83$, strong rockburst tendency; $0.7 \leq K_{i} \leq 0.83$, medium rockburst tendency; $K_{i}<0.7$, no rockburst tendency. However, this index is aimed at small size specimens of coal and rock, and the impact of strip coal pillar geometric size on the rockburst risk is also not considered, resulting in its little significance in the application of strip coal pillar rockburst risk assessment.

Based on the old elastic deformation index and considering the influence of coal pillar geometry size on rockburst risk, this paper proposes a new elastic deformation index of strip coal pillar core zone, which is denoted by $U_{q}$. $U_{q}$ is the ratio of elastic core compression to critical core area compression of loaded strip coal pillar. The elastic deformation index is directly related to the accumulation of deformation energy, which indirectly reflects the relationship between the deformation energy accumulation of strip coal pillar and the critical state of rockburst. The larger elastic deformation index of strip coal pillar core zone, the greater the rockburst risk of strip coal pillar. When the compression amount of strip coal pillar core zone exceeds the critical compression amount of impact instability, it can be considered that the rockburst has occurred. The new elastic deformation index can be expressed as

$$
U_{q}=\frac{u_{0}}{u_{q}}
$$

where $u_{0}$ is the compression of the elastic core of strip coal pillar and $u_{q}$ is the rockburst critical compression of strip coal pillar core zone.

According to the old elastic deformation index of coal and rock, the classification standard of the new elastic deformation index of strip coal pillar core zone is as follows: $U_{q} \leq 0.7$, no rockburst tendency; $0.7<U_{q}<0.83$, medium rockburst tendency; $0.83<U_{q}<1$, strong rockburst tendency; $1 \leq U_{q}$, rockburst has occurred.

\section{Application of Rockburst Risk Evaluation}

4.1. Mining and Geological Condition. The Gucheng Coal Mine is located in Jining city, Shandong Province, China. The average overburden depth of Gucheng Coal Mine is $1070 \mathrm{~m}$, which is a typical deep mine. The current mining seam is \#3 coal seam. The average thickness and dip angle of the coal seam are $8.83 \mathrm{~m}$ and $7.5^{\circ}$, respectively. The Protodyakonov scale of hardness, Poisson's ratio, and elastic modulus of the coal seam are 3.0, 0.22, and $6.72 \mathrm{GPa}$, respectively. The rock strata above the coal seam are, in order, sandy mudstone with $1.88 \mathrm{~m}$ thick and medium sandstone with $18.7 \mathrm{~m}$ thick. This study involves mining panel 3202, which is approximately $116 \mathrm{~m}$ in a strike. A fully mechanized longwall top coal caving method is used for \#3 coal extraction in this working face, with a mechanized mining height of $3.0 \mathrm{~m}$. The top-coal caving height is $5.83 \mathrm{~m} .3202$ panel is located at the east of the mining area 3203 panel with the width $120 \mathrm{~m}$, where the coal has been extracted. The width of the strip coal pillar between the 3203 panel and the 3202 panel is $120 \mathrm{~m}$, as shown in Figure 2.

4.2. Evaluation of Rockburst Risk. According to Section 3 of this paper, rockburst risk evaluation indexes of strip coal pillar are listed in Table 1.

According to A. H. Wilson progressive failure theory, the plastic zone width of strip coal pillar can be expressed as

$$
Y=0.0049 m H \text {, }
$$

where $Y$ is the plastic zone width of strip coal pillar, $m$ is the height of the strip coal pillar, and $H$ is the mining depth.

For the 3202 panel, the height of the strip coal pillar is $8.83 \mathrm{~m}$, the mining depth is $1070 \mathrm{~m}$, while the width of the strip coal pillar is $120 \mathrm{~m}$. Therefore, the plastic zone width of the coal pillar calculated by equation (15) is $46.3 \mathrm{~m}$, and the $a_{Y}$ is $38.6 \%$. According to the evaluation index of $a_{Y}$ in Table 1, the coal pillar of the 3202 panel is of medium rockburst tendency.

Further, $k_{e}$ and $k_{s}$ calculated by equation (9) are $2.11 \times 10^{10}$ and $1.018 \times 10^{11} \mathrm{~N} / \mathrm{m}$, respectively, and the medium stiffness ratio $k$ is 0.207 . According to the evaluation index of $k$ in Table 1, the coal pillar of the 3202 panel is of strong rockburst tendency.

According to the test results, the strain corresponding to the peak load of the coal seam under uniaxial compression is 0.013 . So $u_{c}$ is $0.115 \mathrm{~m}$. Further, the critical compression of the strip coal pillar $u_{q}$ calculated by equation (8) is $0.086 \mathrm{~m}$. However, according to equation (12), $u_{0}$ is still unknown, which needs to be obtained by numerical simulation.

\subsection{Numerical Simulation for the Elastic Deformation Index}

4.3.1. Numerical Model Generation. The FALC3D was used to construct a numerical model. According to the geological conditions of the 3202 working face, the FALC3D was used to construct the numerical calculation model. Considering the influence of boundary effect, coal pillars of $30 \mathrm{~m}$ in width are reserved at the boundary along the direction of length and width, and the dimensions of the model are $222 \mathrm{~m} \times 158 \mathrm{~m} \times 69.5 \mathrm{~m}$. The horizontal displacements of the four vertical planes of the model were restricted in the normal direction, and the vertical displacement at the base of the model was set to zero. The top surface of the model is allowed to move freely. Vertical stress of $26.875 \mathrm{MPa}$ is 


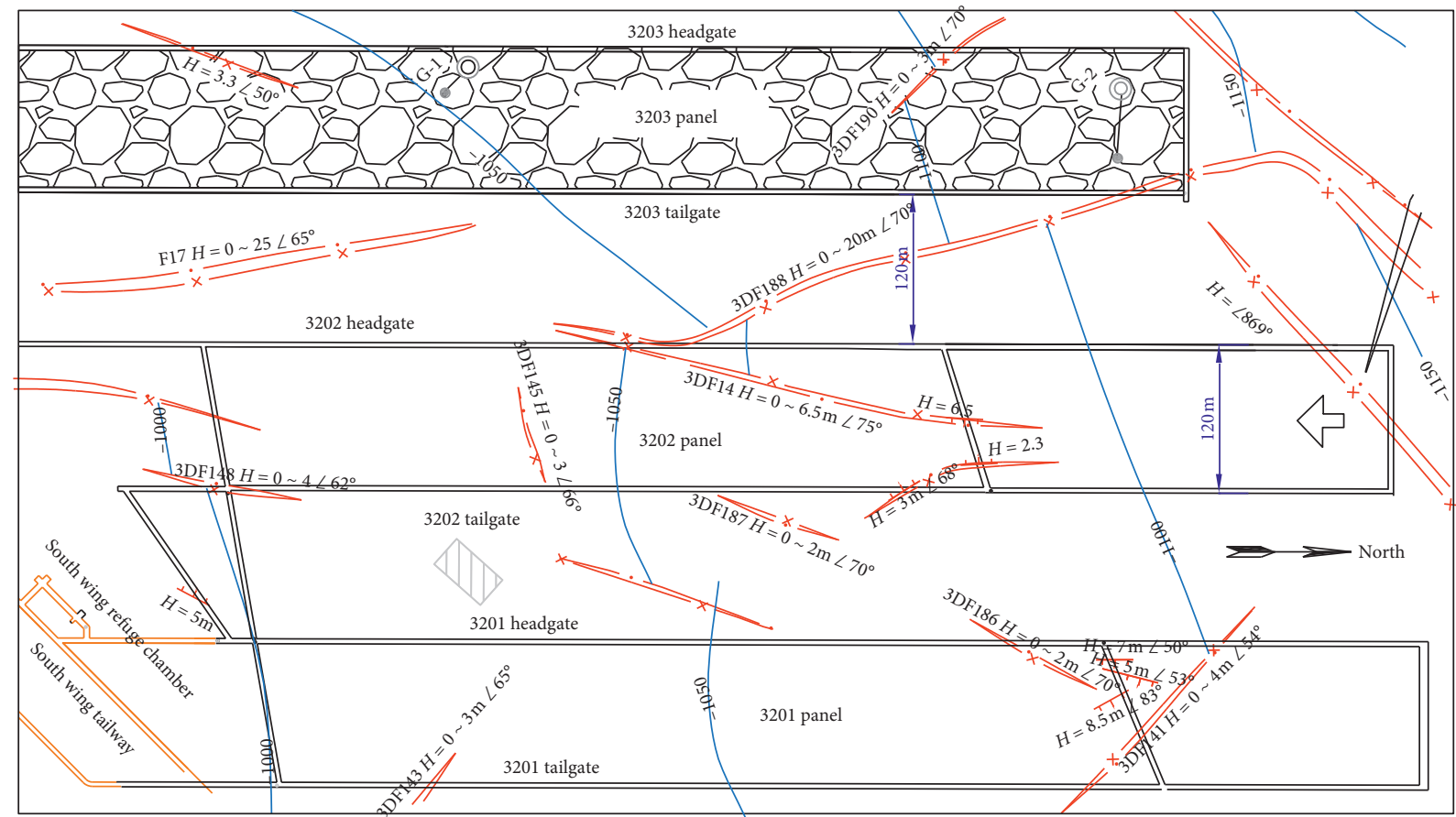

Figure 2: Layout of the 3202 panel.

TABLE 1: Rockburst risk indexes of strip coal pillar.

\begin{tabular}{lccc}
\hline Index & \multicolumn{2}{c}{$\begin{array}{c}\text { Risk classification standard } \\
\text { Medium rockburst } \\
\text { tendency }\end{array}$} & $\begin{array}{c}\text { Strong rockburst tendency } \\
\text { No rockburst tendency }\end{array}$ \\
\hline Medium stiffness ratio of the elastic and plastic zone, $k$ & $k \geq 1.46$ & $0.7<K<1.46$ & $k \leq 0.73$ \\
Plastic zone width ratio, $a_{Y}$ & $a_{Y} \leq 35.4 \%$ & $35.4 \%<a_{Y}<41.5 \%$ & $a_{Y} \geq 41.5 \%$ \\
Elastic deformation index of the core zone, $U_{q}$ & $U_{q} \leq 0.7$ & $0.7<U_{q}<0.83$ & $0.83 \leq U_{q}<1$ \\
\hline
\end{tabular}

applied to the top boundary of the model to simulate the selfweight of the overburden, and the horizontal side pressure coefficient is 0.5 .

The model uses Mohr-Coulomb constitutive relations, and the mechanical properties applied in the model are listed in Table 2.

4.3.2. Evaluation of the Plastic Zone Width Ratio. When the width of the strip coal pillar is $120 \mathrm{~m}$ and the mining width of the 3202 panel varies from $76 \mathrm{~m}$ to $136 \mathrm{~m}$, the plastic zone width ratio of the coal pillar is shown in Figure 3.

As shown in Figure 3, when the mining width of the working face is $76 \mathrm{~m}$ and $96 \mathrm{~m}$, the plastic zone width of the strip coal pillar is $40 \mathrm{~m}$ and $a_{Y}$ is $33.3 \%$. When the mining width of the working face is $116 \mathrm{~m}$ and $136 \mathrm{~m}$, the plastic zone width of the coal pillar is $44 \mathrm{~m}$ and $56 \mathrm{~m}$, respectively, and $a_{Y}$ is $36.7 \%$ and $46.7 \%$, respectively.

The relationship between $a_{Y}$ and mining width is shown in equation (16). When the width of the strip coal pillar is fixed, $a_{Y}$ increases exponentially with the increase of mining width:

$$
\begin{aligned}
& a_{Y}=0.323+0.000031 e^{0.0062 a}, \\
& R^{2}=0.989 .
\end{aligned}
$$

According to equation (16), when the mining width is less than $112 \mathrm{~m}$, there is no rockburst tendency for the strip coal pillar; when the mining width is between $112 \mathrm{~m}$ and $128 \mathrm{~m}$, there is medium rockburst tendency for the strip coal pillar; and when the mining width is greater than $128 \mathrm{~m}$, there is strong rockburst tendency for the strip coal pillar.

When the mining width of the 3202 panel is $116 \mathrm{~m}$ and the width of the strip coal pillar varies from $60 \mathrm{~m}$ to $120 \mathrm{~m}$, the plastic zone width ratio of the coal pillar is shown in Figure 4. When the width of the strip coal pillar is $60 \mathrm{~m}$, the whole coal pillar has a plastic failure and $a_{Y}$ is $100 \%$. When the mining width is fixed, the plastic zone of strip coal pillar decreases with the increase of the width of the coal pillar. When the width of the strip coal pillar is $80 \mathrm{~m}, 100 \mathrm{~m}$, and $120 \mathrm{~m}$, the plastic zone width of the coal pillar is $60 \mathrm{~m}, 44 \mathrm{~m}$, and $44 \mathrm{~m}$, respectively, and $a_{Y}$ is $75.0 \%, 44.0 \%$, and $36.7 \%$, respectively.

As shown in Figure 4, the relationship between $a_{Y}$ and the width of the strip coal pillar is shown in equation (17). 
TABLE 2: Physical and mechanical parameters of the rock mass.

\begin{tabular}{|c|c|c|c|c|c|c|}
\hline Lithology & Thickness (m) & Bulk modulus (GPa) & Shear modulus $(\mathrm{GPa})$ & Cohesion (MPa) & Tensile strength $(\mathrm{MPa})$ & $\begin{array}{l}\text { Friction } \\
\text { angle }\left({ }^{\circ}\right)\end{array}$ \\
\hline Siltstone & 17 & 7.3 & 5.1 & 3.2 & 2.8 & 27 \\
\hline Fine sandstone & 15 & 9.2 & 7.7 & 3.5 & 3.2 & 29 \\
\hline Sandy mudstone & 3.4 & 4.7 & 2.83 & 2.7 & 2.21 & 31.4 \\
\hline Fine sandstone & 5 & 9.2 & 7.7 & 3.5 & 3.2 & 29 \\
\hline Medium sandstone & 19 & 11.8 & 8.1 & 4.3 & 4.84 & 34.1 \\
\hline Sandy mudstone & 2 & 4.7 & 2.83 & 2.7 & 2.21 & 31.4 \\
\hline \#3 coal & 9 & 2.1 & 1.78 & 1.8 & 1.25 & 25 \\
\hline Sandy mudstone & 2.3 & 4.7 & 2.83 & 2.7 & 2.21 & 31.4 \\
\hline Medium sandstone & 21 & 11.8 & 8.1 & 4.3 & 4.84 & 34.1 \\
\hline
\end{tabular}

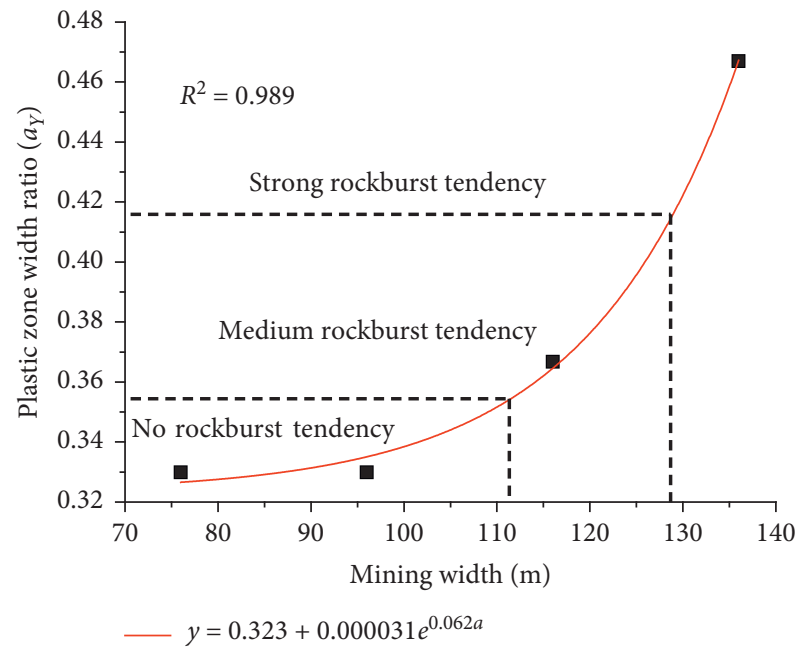

FIGURE 3: Fitting relationship of plastic zone width ratio and mining width.

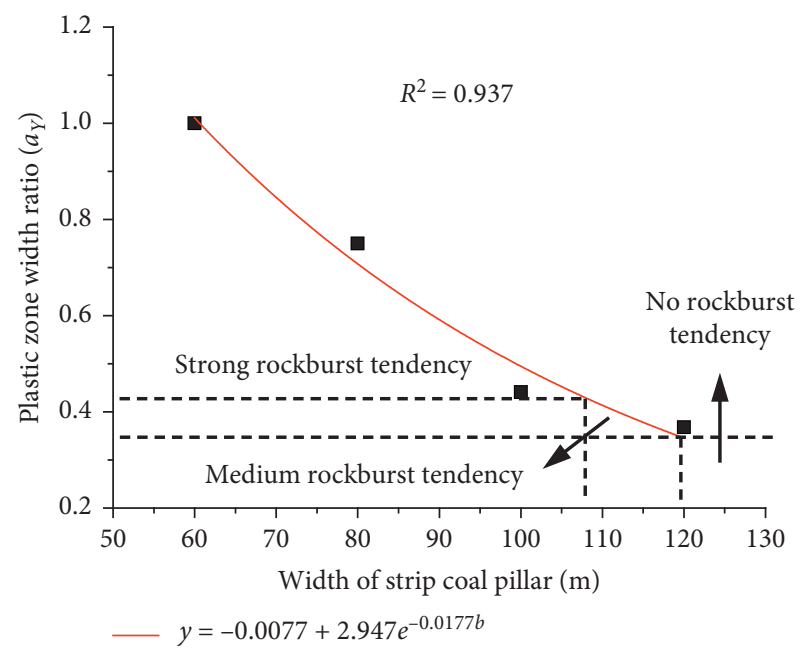

FIGURE 4: Fitting relationship of plastic zone width ratio and strip coal pillar.

When the mining width of the 3202 panel is fixed, $a_{Y}$ decreases exponentially with the increase of the coal pillar width:

$$
\begin{aligned}
& a_{Y}=-0.0077+2.947 e^{-0.0177 b}, \\
& R^{2}=0.937 .
\end{aligned}
$$

According to equation (17), when the width of strip coal pillar is less than $108 \mathrm{~m}$, there is strong rockburst tendency for the strip coal pillar; when the width of strip coal pillar is between $108 \mathrm{~m}$ and $120 \mathrm{~m}$, there is medium rockburst tendency for the coal pillar; and when the width of strip coal pillar is greater than $120 \mathrm{~m}$, there is no rockburst tendency for the coal pillar.

4.3.3. Evaluation of the Elastic Deformation Index. In the numerical simulation, the compression of the strip coal pillar is obtained by measuring the subsidence of the coal pillar roof. When the width of the strip coal pillar is $120 \mathrm{~m}$, the compression of the coal pillar with different mining widths is shown in Figure 5.

It can be seen from Figure 5 that with the increase of mining width, the compression of the coal pillar keeps increasing gradually.

When the mining width is $76 \mathrm{~m}, 96 \mathrm{~m}$, and $116 \mathrm{~m}$, respectively, $U_{0}$ is $0.061 \mathrm{~m}, 0.066 \mathrm{~m}$, and $0.072 \mathrm{~m}$, respectively, and $U_{q}$ is $0.709,0.767$, and 0.837 , respectively. When the mining width is $136 \mathrm{~m}, u_{0}$ reaches $0.129 \mathrm{~m}$, and $U_{q}$ increases to 1.5. As shown in Figure 6, the relationship between the $U_{q}$ and the mining width is shown in

$$
\begin{aligned}
U_{q} & =0.725+0.0000022 e^{0.094 a}, \\
R^{2} & =0.993 .
\end{aligned}
$$

According to equation (18), when the mining width is less than $76 \mathrm{~m}$, there is no rockburst tendency for the coal pillar; when the mining width is between $76 \mathrm{~m}$ and $116 \mathrm{~m}$, there is medium rockburst tendency for the coal pillar; when the mining width is between $116 \mathrm{~m}$ and $126 \mathrm{~m}$, there is strong rockburst tendency for the coal pillar; and when the mining width is greater than $126 \mathrm{~m}$, the rockburst has occurred, and $U_{q}$ increases rapidly which can be shown in Figure 6 .

When the mining width of the 3202 panel is $116 \mathrm{~m}$ and the width of the strip coal pillar varies from $60 \mathrm{~m}$ to $120 \mathrm{~m}$, the compression of the coal pillar is shown in Figure 7.

It can be seen from Figure 7 that with the decrease of the width of strip coal pillar, the compression of the coal pillar keeps increasing gradually. When the width of the strip coal 


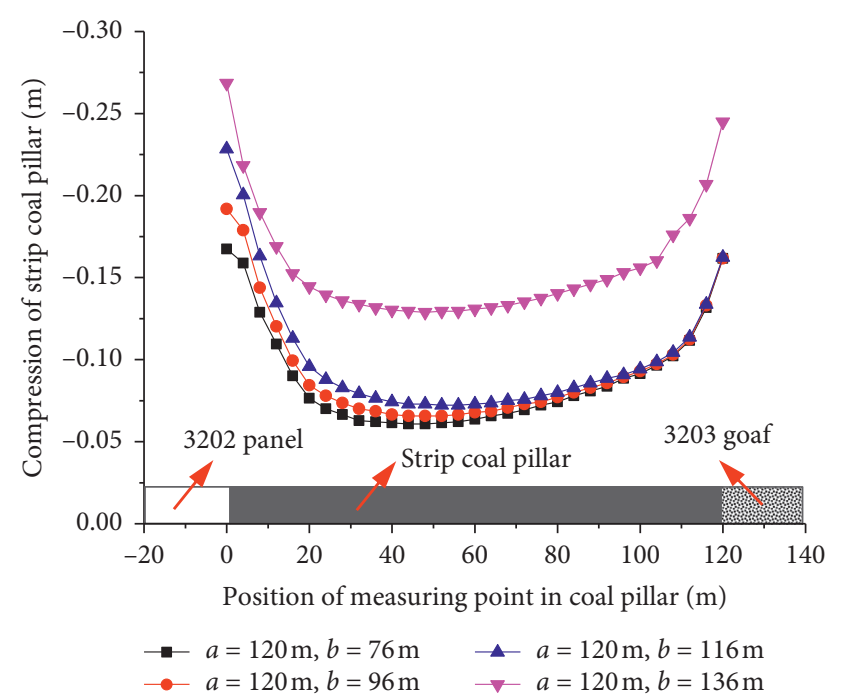

Figure 5: Compression of strip coal pillar under different mining widths.

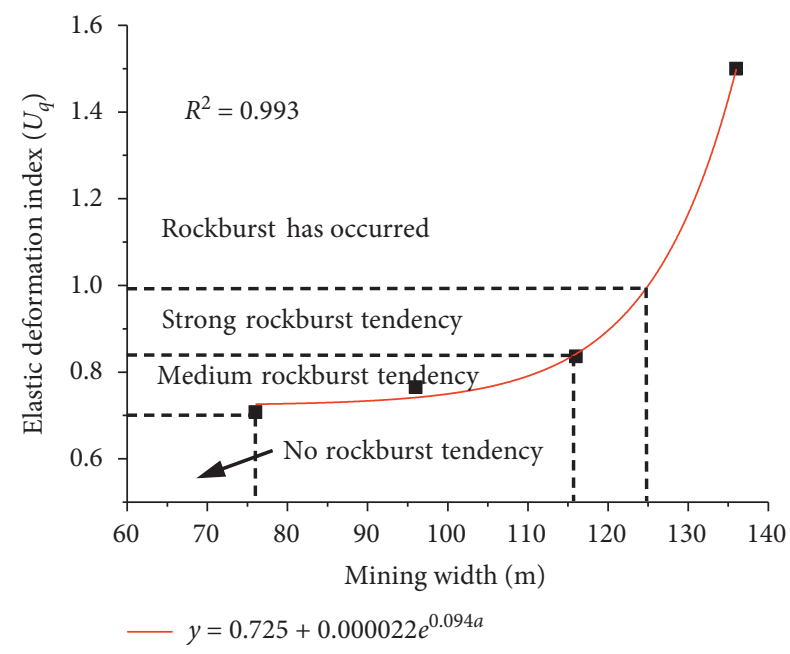

FIGURE 6: Fitting relationship of elastic deformation index of kernel zone and mining width.

pillar is $120 \mathrm{~m}$ and $100 \mathrm{~m}$, respectively, $u_{0}$ is $0.072 \mathrm{~m}$ and $0.083 \mathrm{~m}$, respectively, and $U_{q}$ is 0.837 and 0.965 , respectively. When the width of the coal pillar is $80 \mathrm{~m}$ and $60 \mathrm{~m}$, respectively, $u_{0}$ is $0.128 \mathrm{~m}$ and $0.160 \mathrm{~m}$, respectively, and $U_{q}$ is 1.49 and 1.86 , respectively. As shown in Figure 8, the relationship between $U_{q}$ and the width of the coal pillar is shown in

$$
\begin{aligned}
U_{q} & =0.0274+4.457 e^{-0.0146 b}, \\
R^{2} & =0.923 .
\end{aligned}
$$

According to equation (19), when the width of strip coal pillar is greater than $114 \mathrm{~m}$, there is medium rockburst tendency for the coal pillar; when the width of strip coal

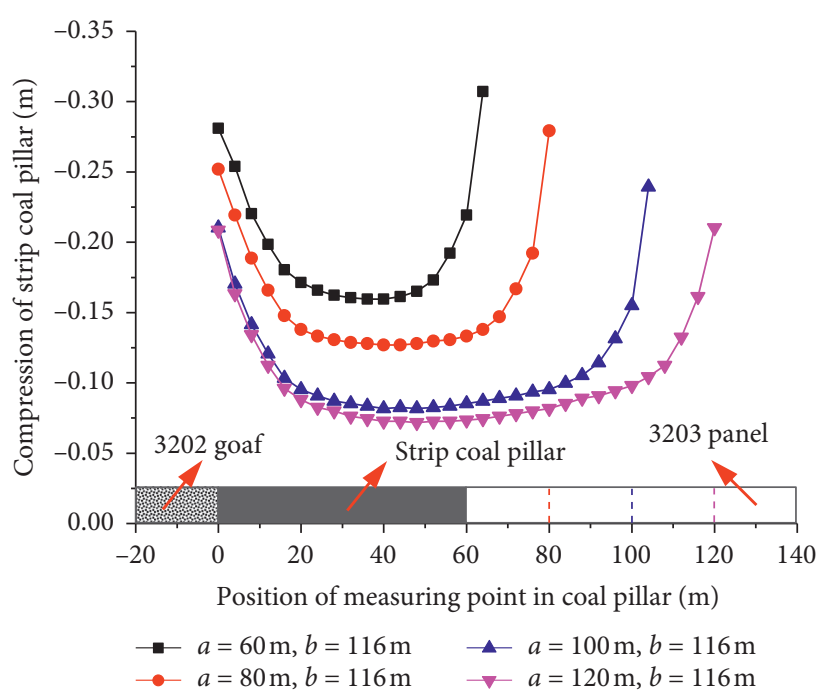

Figure 7: Compression of strip coal pillar under different coal pillar widths.

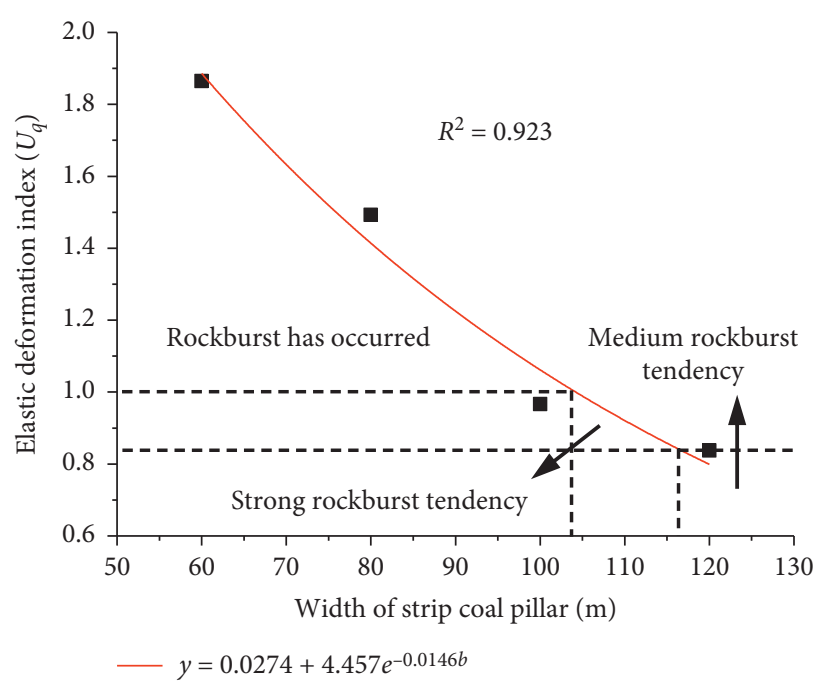

FIGURE 8: Fitting relationship of $U_{q}$ and the width of the coal pillar.

pillar is between $98 \mathrm{~m}$ and $114 \mathrm{~m}$, there is strong rockburst tendency for the coal pillar; and when the width of strip coal pillar is less than $98 \mathrm{~m}$, the rockburst has occurred, and $U_{q}$ increases rapidly.

4.4. Comprehensive Evaluation Results. According to the above simulation results, the rockburst risk of strip coal pillar under different mining widths and the width of coal pillar conditions is shown in Figure 9. The results of rockburst risk evaluation in this paper are compared with those of the traditional rockburst tendency identification test in the laboratory, as shown in Table 3. 


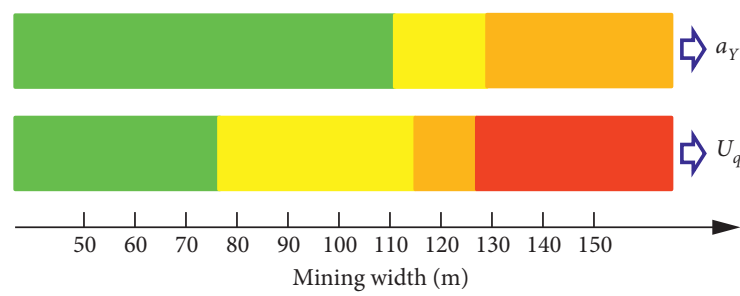

No rockburst tendency

Strong rockburst tendency
Medium rockburst tendency

Rockburst has occurred

(a)

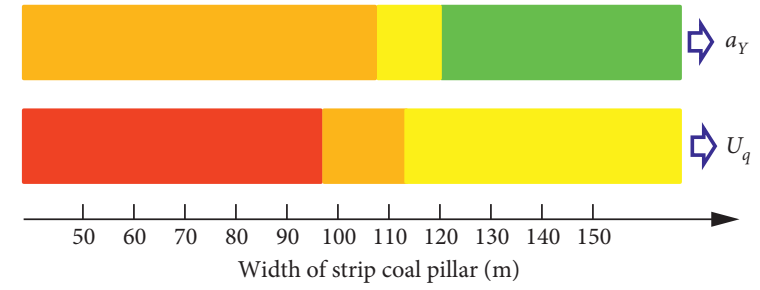

No rockburst tendency

Strong rockburst tendency

Medium rockburst tendency

(b)

FIGURE 9: Rockburst risk under different mining widths and the width of strip coal pillar: (a) width of strip coal pillar is fixed as 120 m; (b) mining width is fixed as $120 \mathrm{~m}$.

TABLE 3: Rockburst risk evaluation results of 3202 panel.

\begin{tabular}{lccc}
\hline Classification & Index & Value & Evaluation conclusion \\
\hline \multirow{4}{*}{ Traditional rockburst tendency identification test } & Dynamic failure time, DT $(\mathrm{ms})$ & 56 & Weak rockburst tendency \\
& Impact energy index, $W_{\mathrm{ET}}$ & 5.32 & Strong rockburst tendency \\
& Elastic energy index, $K_{E}$ & 4.65 & Weak rockburst tendency \\
& Uniaxial compressive strength, $R_{C}(\mathrm{MPa})$ & 13.5 & Weak rockburst tendency \\
\hline \multirow{2}{*}{ Theoretical calculation results in this paper } & $k$ & 0.207 & Strong rockburst tendency \\
& $a_{Y}$ & $38.45 \%$ & Medium rockburst tendency \\
\hline \multirow{2}{*}{ Numerical simulation results in this paper } & $a_{Y}$ & $36.7 \%$ & Medium rockburst tendency \\
& $U_{q}$ & 0.837 & Strong rockburst tendency \\
\hline
\end{tabular}

It can be seen from Figure 9 and Table 3 that under the same mining width and width of the coal pillar, the rockburst risk obtained by $U_{q}$ is higher than the evaluation result of $a_{Y}$. For the sake of safety, the evaluation result of $U_{q}$ is adopted. So, the strip coal pillar of the 3202 panel has a strong rockburst tendency.

As shown in Table 3, the result of the traditional rockburst tendency identification test of \#3 coal in Gucheng Coal Mine is a weak rockburst tendency. Moreover, the comprehensive index method [34] is used to evaluate the rockburst risk of the 3202 panel, and the evaluation result shows that the 3202 panel is of medium rockburst tendency. However, the field monitoring results [35] showed that the deformation of the roadway on the side of the strip coal pillar was very serious, the maximum deformation was more than $1100 \mathrm{~mm}$, large energy microseismic events gather relatively, and the rockburst risk of the coal pillar was high. It can be seen that the rockburst risk evaluation result in this paper is more in line with the actual situation. Therefore, the rockburst risk evaluation indexes of strip coal pillar proposed in this paper are more accurate and reasonable.

According to Figure 9, from the perspective of reducing the rockburst risk, for the strip mining of Gucheng Coal Mine, when the mining width of the working face is $116 \mathrm{~m}$, the width of strip coal pillar cannot be less than $98 \mathrm{~m}$. The width of strip coal pillar of the 3202 panel is $120 \mathrm{~m}$, which meets the above requirements. Therefore, the rockburst risk of the coal pillar of the 3202 panel is relatively low.

\section{Conclusions}

(1) The traditional test method of coal and rockburst risk ignores the influence of coal pillar geometry size, and the evaluation results have little significance for the field guidance of deep strip mining. Considering the influence of mining width and coal pillar width in strip mining, three new indexes were put forward to evaluate the rockburst risk of deep strip mining, namely, the medium stiffness ratio $(k)$ of the elastic and plastic zone in coal pillar, the plastic zone width ratio $\left(a_{Y}\right)$, and the elastic deformation index $\left(U_{q}\right)$ of the core zone.

(2) The stiffness ratio index $(k)$ of the elastic-plastic zone indicates the degree of strain-softening during the loading process of strip coal pillar. The plastic zone width ratio $\left(a_{Y}\right)$ of strip coal pillar can be measured by the drilling cutting method, which has strong field operability. And the elastic deformation index $\left(U_{q}\right)$ indirectly reflects the relationship between the deformation energy accumulation of strip coal pillar and the critical state of rockburst. For these three indexes, the larger the index value is, the greater the rockburst risk is.

(3) According to the new evaluation indexes of this paper, the strip coal pillar of the 3202 panel of Gucheng Coal Mine is in danger of strong rockburst. Compared with the results of the traditional 
rockburst tendency identification test and comprehensive index method, the evaluation result in this paper is more in line with the actual situation.

(4) From the point of view of prevention and control of rockburst, the design principle of strip mining in Gucheng Coal Mine is put forward; that is, when the mining width of the working face is $116 \mathrm{~m}$, the width of the strip coal pillar cannot be less than $98 \mathrm{~m}$.

\section{Data Availability}

All data supporting this study are included within the article.

\section{Conflicts of Interest}

The authors declare no conflicts of interest.

\section{Acknowledgments}

This work was supported by the Shandong Provincial Natural Science Foundation, China (ZR2019BEE001, ZR2018MEE009) and Key Research and Development Projects of Shandong Province, China (2019GSF111038).

\section{References}

[1] Z. Wen, E. Xing, S. Shi, and Y. Jiang, "Overlying strata structural modeling and support applicability analysis for large mining-height stopes," Journal of Loss Prevention in the Process Industries, vol. 57, pp. 94-100, 2019.

[2] S. Hu, Y. Tan, H. Zhou et al., "Anisotropic modeling of layered rocks incorporating planes of weakness and volumetric stress," Energy Science \& Engineering, vol. 8, no. 3, pp. 789-803, 2020.

[3] N. Jiang, C. Wang, H. Pan, D. Yin, and J. Ma, "Modeling study on the influence of the strip filling mining sequence on mining-induced failure," Energy Science \& Engineering, vol. 8, no. 6, pp. 2239-2255, 2020.

[4] Y. Wang, B. Liu, and Y. Qi, "A risk evaluation method with an improved scale for tunnel engineering," Arabian Journal for Science and Engineering, vol. 43, no. 4, pp. 2053-2067, 2018.

[5] W. P. Huang, C. Li, L. W. Zhang, Q. Yuan, Y. S. Zheng, and Y. Liu, "In situ identification of water-permeable fractured zone in overlying composite strata," International Journal of Rock Mechanics and Mining Sciences, vol. 105, pp. 85-97, 2018.

[6] F. X. Jiang, J. L. Wen, W. S. Bai, G. L. Wang, and M. Li, "Rock burst risk in surrounding abscission layer of overlying high key strata in deep strip mining mines," Journal of China University of Mining and Technology, vol. 47, no. 1, pp. 40-47, 2018.

[7] J. Wang, P. Qiu, J. Ning, L. Zhuang, and S. Yang, “A numerical study of the mining-induced energy redistribution in a coal seam adjacent to an extracted coal panel during longwall face mining: a case study," Energy Science \& Engineering, vol. 8, no. 3, pp. 817-835, 2020.

[8] Q. Liu, J. Chai, S. Chen, D. Zhang, Q. Yuan, and S. Wang, "Monitoring and correction of the stress in an anchor bolt based on pulse pre-pumped brillouin optical time domain analysis," Energy Science \& Engineering, vol. 8, no. 6, pp. 2011-2023, 2020.

[9] G. C. Zhang, Z. J. Wen, S. J. Liang et al., "Ground response of a gob-side entry in a longwall panel extracting $17 \mathrm{~m}$-thick coal seam: a case study," Rock Mechanics and Rock Engineering, vol. 53, no. 2, pp. 497-516, 2020.

[10] G. C. Zhang, L. J. Chen, Z. J. Wen et al., "Squeezing failure behavior of roof-coal masses in a gob-side entry driven under unstable overlying strata," Energy Science and Engineering, vol. 8 , no. $1,2020$.

[11] T.-B. Zhao, W.-Y. Guo, Y.-L. Tan, C.-P. Lu, and C.-W. Wang, "Case histories of rock bursts under complicated geological conditions," Bulletin of Engineering Geology and the Environment, vol. 77, no. 4, pp. 1529-1545, 2018.

[12] P. X. Zhao, S. G. Li, C. Ho, H. F. Lin, and R. S. Zhuo, "Crack propagation and material characteristics of rocklike specimens subject to different loading rates," Journal of Materials in Civil Engineering, vol. 31, no. 7, pp. 1-17, 2019.

[13] Y. D. Jiang and Y. X. Zhao, "State of the art: investigation on mechanism, forecast and control of coal bumps in China," Chinese Journal of Rock Mechanics and Engineering, vol. 34, no. 11, pp. 2188-2204, 2015.

[14] Y. Tan, D. Fan, X. Liu, S. Song, X. Li, and H. Wang, "Numerical investigation of failure evolution for the surrounding rock of a super-large section chamber group in a deep coal mine," Energy Science \& Engineering, vol. 7, no. 6, pp. 3124-3146, 2019.

[15] J. M. Yao, Y. Y. Yan, S. Z. Li, J. W. Yang, and X. Wang, "Damage index of coal seam rock burst proneness," Journal of China Coal Society, vol. 36, no. S2, pp. 353-357, 2011.

[16] C. D. Su, B. B. Gao, R. F. Yuan, and J. Yang, "Outburstproneness index and their correlation analysis of coal seams in Pingdingshan mine area," Journal of China Coal Society, vol. 39, no. S1, pp. 8-14, 2014.

[17] Y. S. Pan, L. Geng, and Z. H. Li, "Research on evaluation indices for impact tendency and danger of coal seam," Journal of China Coal Society, vol. 35, no. 12, pp. 1975-1978, 2010.

[18] B. Y. Jiang, L. G. Wang, Y. L. Lu, C. Q. Wang, and D. Ma, "Combined early warning method for rockburst in a deep island, fully mechanized caving face," Arabian Journal of Geosciences, vol. 9, no. 20, p. 743, 2016.

[19] Z. Zhang, M. Deng, J. Bai, X. Yu, Q. Wu, and L. Jiang, "Strain energy evolution and conversion under triaxial unloading confining pressure tests due to gob-side entry retained," International Journal of Rock Mechanics and Mining Sciences, vol. 126, Article ID 104184, 2020.

[20] T. B. Zhao, W. Zhang, and W. Y. Guo, "Digital image correlation analysis of displacement based on corrected three surface fitting algorithm," Complexity, vol. 2019, Article ID 4620858, 9 pages, 2019.

[21] J. Wang, J. G. Ning, J. Q. Jiang, and T. T. Bu, "Structural characteristics of strata overlying of a fully mechanized longwall face: a case study," Journal of the Southern African Institute of Mining and Metallurgy, vol. 118, pp. 1195-1204, 2018.

[22] J. Wang, J. G. Ning, P. Q. Qiu, S. Yang, and H. F. Shang, "Microseismic monitoring and its precursory parameter of hard roof collapse in longwall faces: a case study," Geomechanics and Engineering, vol. 17, no. 4, pp. 375-383, 2019.

[23] C.-P. Lu, Y. Liu, N. Zhang, T.-B. Zhao, and H.-Y. Wang, "Insitu and experimental investigations of rockburst precursor and prevention induced by fault slip," International Journal of Rock Mechanics and Mining Sciences, vol. 108, pp. 86-95, 2018.

[24] C.-P. Lu, B. Liu, B. Liu, Y. Liu, H.-Y. Wang, and H. Zhang, "Anatomy of mining-induced fault slip and a triggered rockburst," Bulletin of Engineering Geology and the Environment, vol. 78, no. 7, pp. 5147-5160, 2019. 
[25] T. B. Zhao, Y. C. Yin, and Y. L. Tan, "Safe mining and new prediction model in coal seam with rock burst induced by roof," Disaster Advances, vol. 5, no. 4, pp. 691-695, 2012.

[26] W. L. Yang, F. X. Jiang, J. L. Wen, Y. Liu, and Q. D. Wei, "Study on mechanisms of rock burst induced by a left coal pillar and prevention technology," Journal of Mining and Safety Engineering, vol. 31, no. 6, pp. 876-880, 2014.

[27] Y. Tan, W. B. Guo, and Y. H. Zhao, "Engineering stability and instability mechanism of strip Wongawilli coal pillar system based on catastrophic theory," Journal of China Coal Society, vol. 41, no. 7, pp. 1667-1674, 2016.

[28] B.-Y. Jiang, S.-T. Gu, L.-G. Wang, G.-C. Zhang, and W.-S. Li, "Strainburst process of marble in tunnel-excavation-induced stress path considering intermediate principal stress," Journal of Central South University, vol. 26, no. 4, pp. 984-999, 2019.

[29] Q. L. Zhang, X. G. Cao, Y. L. Wang, and L. H. Qiang, "Stability analysis of stope roof-pillar based on cusp catastrophe model," China Safety Science Journal, vol. 21, no. 10, pp. 52-57, 2011.

[30] Y. L. Tan, C. X. Liu, and T. B. Zhao, On Nonlinear Rock Mechanics, China Coal Industry Publishing House, Beijing, China, 2008.

[31] Y. S. Pan and M. T. Zhang, "The study of coalburst by catas trophic theory," Journal of Fuxin Mining Institute, vol. 11, no. 1, pp. 12-18, 1992.

[32] Q. X. Qi and L. M. Dou, Theory and Technology of Rockburst, China University of mining and Technology Press, Xuzhou, China, 1997.

[33] Q. X. Qi, Y. W. Peng, H. Y. Li, J. Q. Li, Y. G. Wang, and C. R. Li, "Study of bursting liability of coal rock," Chinese Journal of Rock Mechanics and Engineering, vol. 30, no. S1, pp. 2736-2742, 2011.

[34] O. Y. Zhenhua, G. H. Zhang, H. Y. Qin, R. Peng, and X. H. Liu, "Improved comprehensive index evaluation method and its application on rockburst hazard of gas coal seam," Coal Science and Technology, vol. 46, no. 10, pp. 30-36, 2018.

[35] J. L. Wen, Rockburst Mechanism of Skip Mining in Deep Coal Mines and its Application, Doctoral thesis, University of Science and Technology Beijing, Beining, China, 2018. 